\title{
Oral Health Knowledge and Practices among Diverse University Students with Access to Free Dental Care: A Cross-Sectional Study
}

\author{
Ola B. Al-Batayneh ${ }^{*}$, Arwa I. Owais ${ }^{1}$, Yousef S. Khader ${ }^{2}$ \\ ${ }^{1}$ Department of Preventive Dentistry, Jordan University of Science and Technology, Irbid, Jordan \\ ${ }^{2}$ Departments of Public Health, Community Medicine, and Family Medicine, Jordan University of Science and \\ Technology, Irbid, Jordan \\ Email: olabt@just.edu.jo
}

Received 30 January 2014; revised 3 March 2014; accepted 12 March 2014

Copyright (C) 2014 by authors and Scientific Research Publishing Inc.

This work is licensed under the Creative Commons Attribution International License (CC BY). http://creativecommons.org/licenses/by/4.0/

(c) (i) Open Access

\begin{abstract}
Aim: The aim of this study was to investigate oral health knowledge and practices among undergraduate university students from various disciplines with access to free dental care. Materials and Methods: A total of $\mathbf{7 0 9}$ questionnaires were filled out. Data collected included: demographic data, oral health knowledge, and self-reported oral health practices and dental service utilization. Descriptive statistics and Chi-square analysis were performed; significance level was set at $\mathbf{P}<$ 0.05. Mean age was $20.8 \pm 1.5$ years. Results: There were $(90.1 \%)$ of students who considered the toothbrush an oral hygiene aid, $(\mathbf{9 1 . 1 \% )}$ thought fluoride was beneficial to teeth, and almost $(\mathbf{8 0} \%)$ students believed smoking has harmful effects on oral health. Regarding oral health practices, nearly half of the samples reported twice daily tooth-brushing, one-third received regular dental check-ups, and half visited the dentist because of pain or bleeding gums; fear was the main reason for not visiting the dentist. Females primarily visited the dentist for esthetic reasons $(70 \%)$ and males upon complaint $(59.8 \%)$. Oral health knowledge and practices among university students were poor. Conclusion: Dental students showed higher knowledge and better practices among disciplines studied. It is also important that dental hygienists take an active role in educating students in the aspect of oral health.
\end{abstract}

\section{Keywords}

Oral Health; Knowledge; Practices; University; Students

\footnotetext{
${ }^{*}$ Corresponding author.
}

How to cite this paper: Al-Batayneh, O.B., et al. (2014) Oral Health Knowledge and Practices among Diverse University Students with Access to Free Dental Care: A Cross-Sectional Study. Open Journal of Stomatology, 4, 135-142. 


\section{Introduction}

Oral hygiene is a significant factor in oral disease prevention. Given the educational level of university students, the concept of oral health, its importance, and practice are assumed to be easily understood and applied by them, irrespective of their discipline [1]. It is presumed that mass media, dental staff and dental literature are the main sources of oral health information for the public [2]. By maintaining oral health, dental health providers become role models for their patients. Dental students must acquire knowledge, beliefs, attitudes and practices which positively affect the oral health of their patients, families and colleagues from other disciplines [3].

Many studies about oral hygiene behaviors have been conducted among university students. Some have focused on the knowledge, attitude, and practices of non-professional college students towards oral health [4] [5], and others studied dental students [6]-[10], students with medical background (including medicine, dental, nursing, and pharmacy students) [11] [12], or compared dental, dental technology and dental hygiene students [13]. One study was conducted in a Turkish student population but excluded dental students [14] and another compared medical and engineering Indian students [1]. However, those comparing the general university student population have been sparse and little care has been paid to the context in whether dental students differ from other students with respect to their knowledge and practices towards oral health and oral self-care regimens.

The campus population of Jordan University of Science and Technology provided a unique opportunity for assessing the oral hygiene knowledge and practices of university students from diverse disciplines since the university has a dental school offering free dental care to students so, access to care is not a problem; it is the student knowledge and dental awareness in getting such services. Thus, this study aimed to assess oral health knowledge and practices of university students from diverse disciplines when they have equal access to free dental care.

\section{Materials and Methods}

\subsection{Ethical Clearance}

The study was supported by the Jordan University of Science and Technology, grant number 227/2009. The Jordan University of Science and Technology's Institutional Research Board (IRB) ethically approved the survey protocol.

\subsection{Study Population and Sampling}

During the study period, several college buildings at the university campus (cafeterias, library group's rooms, lecture buildings, corridors, student union/clubs and recreational areas) were visited, and undergraduate students who were available in these locations were invited to participate in the study. The college buildings were visited more than one time in different days and met the students to reach total of 700 students. Inclusion criteria included undergraduate students, studying in any discipline in the university, and fully completing the questionnaire.

A cover letter attached to the questionnaire provided information about the survey and invited student participation. Participant consent was obtained prior to asking them to answer the questionnaire. The questionnaires were hand-distributed by a group of fifth year dental students as part of a research project course. University students were asked to return the questionnaire after answering independently without asking the student in order to avoid any bias. Confidentiality was maintained throughout the study as the questionnaires were anonymous and a numbering system was used. Prior to distribution of the questionnaire, the students were informed that their participation was voluntary and that refusing to participate would not affect their grades.

\subsection{Questionnaire}

A 23-item, researcher-designed, self-administered questionnaire was used to collect the data. The questionnaire was constructed using multiple-choice or true-false format and consisted of three parts. The average time to complete the survey was approximately ten minutes. Content and face validity of the questionnaire were tested with members of the target population $(n=30)$. Test-retest reliability was completed with a separate sub-group from the target population, i.e., 25 students from different disciplines were asked to answer the questionnaire twice (one-week apart). 
The questionnaire was divided into three sections:

Section I: Demographic variables of the study sample. Eight questions addressed age, sex, year of study, university, faculty, both parents' educational level, number of family members, and smoking behavior.

Section II: Oral health knowledge. Eight questions addressed knowledge about the appropriate age for the first dental visit, benefit of different oral hygiene aids, benefit of fluoride for teeth, toothpaste choice, harmful effects of smoking on oral health, diet, the effect of plaque on oral health, and impact of oral health on general health.

Section III: Self-reported oral health practices and dental service utilization. Seven questions addressed frequency of tooth-brushing, sugar intake, and routine dental check-ups, date of the last dental visit, reasons for visiting and not visiting the dentist and person's evaluation of his/her oral health.

\subsection{Statistical Analysis}

Data analysis was done using Statistical Package for Social Sciences (SPSS) computer software (SPSS 15.0, inc., Chicago, USA). Descriptive statistics were used to summarize responses, which were then subjected to Chisquare analysis to assess various relationships. Significance level was set at $\mathrm{P}<0.05$.

\section{Results}

\subsection{Demographic Characteristics of the Study Sample}

A total of one-thousand students were surveyed; 291 questionnaires were excluded by the principal investigator due to incomplete surveys and data from 709 questionnaires were analyzed yielding a response rate of $70.9 \%$. The sample included students from several disciplines aged $18-25$ years (mean $(\mathrm{SD})=20.8(1.5)$ ), with the majority coming from large families. Dental students comprised (43.7\%) of the total sample. The demographic characteristics of the respondents are shown in Table 1.

Table 1. Demographic characteristics of the study subjects.

\begin{tabular}{|c|c|c|}
\hline \multicolumn{2}{|r|}{ Demographic variable } & \multirow{2}{*}{$\begin{array}{c}\mathbf{N}(\%) \\
153(21.5 \%)\end{array}$} \\
\hline \multirow{3}{*}{ Age } & 18 - 19 years old & \\
\hline & 20 - 22 years old & $458(64.6 \%)$ \\
\hline & 23 - 25 years old & $98(13.9 \%)$ \\
\hline \multirow{2}{*}{ Sex } & Male & $333(47.0 \%)$ \\
\hline & Female & $376(53.0 \%)$ \\
\hline \multirow{4}{*}{ Year of study } & $1^{\text {st }}$ and $2^{\text {nd }}$ year & $261(36.8 \%)$ \\
\hline & $3^{\text {rd }}$ and $4^{\text {th }}$ year & $330(46.5 \%)$ \\
\hline & $5^{\text {th }}$ year and above & $118(16.6 \%)$ \\
\hline & Dental students & $310(43.7 \%)$ \\
\hline \multirow[t]{2}{*}{ Faculty } & $\begin{array}{l}\text { Engineering, computer science, science and literature, others } \\
\text { (religion, economy and education) }\end{array}$ & $226(31.9 \%)$ \\
\hline & Medicine, nursing and pharmacy & $173(24.4 \%)$ \\
\hline \multirow{2}{*}{ Educational level/father } & Less than university education & $257(36.2 \%)$ \\
\hline & University or higher education & $452(63.8 \%)$ \\
\hline \multirow{2}{*}{ Educational level/mother } & Less than university education & $459(64.7 \%)$ \\
\hline & University or higher education & $250(35.3 \%)$ \\
\hline \multirow[b]{2}{*}{ Number of family members } & $<5$ members & $54(7.6 \%)$ \\
\hline & 5 - 6 members & $246(34.7 \%)$ \\
\hline \multirow{4}{*}{ Smoking } & $>6$ members & $409(57.7 \%)$ \\
\hline & Yes & $356(50.2 \%)$ \\
\hline & No & $353(49.8 \%)$ \\
\hline & Total & $709(100 \%)$ \\
\hline
\end{tabular}




\subsection{Oral Health Knowledge}

Table 2 shows the oral health knowledge of the students. Only (12.8\%) believed that timing of the first dental visit should be at no later than the first year. The majority of students (90.1\%) considered the toothbrush an oral hygiene and caries-preventive aid. Dental students were the highest among all to use auxiliary oral hygiene aids and base their choice of toothpaste upon fluoride content, but pharmacy students were the highest to use Chlorhexidine ${ }^{\circledR}$ mouth-rinse (92.6\%). There were (91.1\%) of students who believed that fluoride was beneficial to teeth. A preponderance of students, mostly females, demonstrated good knowledge about harmful effects of smoking (80\%), diet and plaque on oral health and the impact of a person's oral health on his/her general health. Dental students showed the highest knowledge level in all areas of oral health knowledge, $(\mathrm{P}<0.05)$.

\subsection{Self-Reported Oral Health Practices and Dental Service Utilization}

In general, nearly half of the sample reported to brush their teeth twice daily, one-third to receive regular dental check-ups, and half to visit the dentist because of pain or bleeding gums. Self-reported oral health practices and dental service utilization are presented in Table 3. Dental students were the majority among all disciplines to brush three times daily (57.1\%). The majority of females also tended to brush their teeth 2 - 3 times daily, and to not eat sweets.

Table 2. Oral health knowledge of the study subjects.

\begin{tabular}{|c|c|c|}
\hline \multicolumn{2}{|c|}{ Oral health knowledge variables } & $N=709$ \\
\hline \multirow{6}{*}{$\begin{array}{l}\text { Knowledge about the appropriate age } \\
\text { for the first dental visit }\end{array}$} & No later than first year in life & $91(12.8 \%)$ \\
\hline & During childhood ( 3 - 16 years) & $537(75.8 \%)$ \\
\hline & No need for this visit & $81(11.4 \%)$ \\
\hline & Toothbrush & $639(90.1 \%)$ \\
\hline & Siwak & $210(29.6 \%)$ \\
\hline & Dental floss & $240(33.9 \%)$ \\
\hline \multirow{4}{*}{$\begin{array}{l}\text { Knowledge about the benefit } \\
\text { of different oral hygiene aids }\end{array}$} & Chlorhexidine ${ }^{\circledR}$ mouth-rinse & $267(37.7 \%)$ \\
\hline & Fluoride mouth-rinse & $267(37.7 \%)$ \\
\hline & Tooth Mousse ${ }^{\mathrm{TM}}$ & $19(2.7 \%)$ \\
\hline & Xylitol chewing gum & $219(30.9 \%)$ \\
\hline \multirow[t]{3}{*}{ Knowledge about benefit of fluoride for teeth } & Fluoride is useful for teeth & $646(91.1 \%)$ \\
\hline & Flavor & $253(35.7 \%)$ \\
\hline & Price & $113(15.9 \%)$ \\
\hline \multirow[t]{4}{*}{ The choice of toothpaste is based on } & Fluoride content & $307(43.3 \%)$ \\
\hline & Tooth-whitening effect & $191(26.9 \%)$ \\
\hline & Trademark & $159(22.4 \%)$ \\
\hline & Smoking causes gingival inflammation & $542(76.4 \%)$ \\
\hline \multirow{4}{*}{$\begin{array}{l}\text { Knowledge about smoking and its } \\
\text { harmful effects on oral health }\end{array}$} & Smoking causes oral cancer & $474(66.9 \%)$ \\
\hline & Smoking causes staining of teeth & $581(81.9 \%)$ \\
\hline & Smoking has no negative effect on teeth & $155(21.9 \%)$ \\
\hline & Sugar is harmful to teeth & $403(56.8 \%)$ \\
\hline \multirow{4}{*}{ Knowledge about diet } & Fresh fruits and vegetables are good for teeth & $346(48.8 \%)$ \\
\hline & Cheese is good for teeth & $286(40.3 \%)$ \\
\hline & Soft drinks and juices have an erosive potential to teeth & $603(85.0 \%)$ \\
\hline & Plaque causes gingival inflammation and dental caries/cavities & $451(63.6 \%)$ \\
\hline \multirow{3}{*}{ Knowledge about the effect of plaque on oral health } & Plaque only causes dental caries/cavities & $154(21.7 \%)$ \\
\hline & Plaque only causes gingival inflammation & $71(10.0 \%)$ \\
\hline & Didn't know the effect of plaque on oral health & $33(4.7 \%)$ \\
\hline Knowledge about impact of oral health on general health & Oral health of a person has an impact on his/her general health & $613(86.5 \%)$ \\
\hline
\end{tabular}


Table 3. Self-reported oral health practices and dental service utilization.

\begin{tabular}{|c|c|c|}
\hline \multicolumn{2}{|c|}{ Self-reported oral health practice } & $\mathbf{N}(\%)$ \\
\hline \multirow{4}{*}{ Frequency of tooth-brushing } & Once daily & $186(26.2 \%)$ \\
\hline & Twice daily & $373(52.6 \%)$ \\
\hline & Three times daily & $133(18.8 \%)$ \\
\hline & Do not brush teeth regularly & $17(2.4 \%)$ \\
\hline \multirow{4}{*}{ Frequency of sugar intake } & Once daily & $306(43.1 \%)$ \\
\hline & More than once daily & $262(37.0 \%)$ \\
\hline & Once or twice weekly & $117(16.5 \%)$ \\
\hline & Don't eat sweets & $24(3.4 \%)$ \\
\hline \multirow[t]{2}{*}{ Frequency of routine dental check-ups } & Subjects receive routine dental check-ups & $206(29.1 \%)$ \\
\hline & Less than a year & $403(56.7 \%)$ \\
\hline \multirow[t]{3}{*}{ Date of the last dental visit } & Since 1 - 3 years & $180(25.4 \%)$ \\
\hline & Since more than 3 years & $127(17.9 \%)$ \\
\hline & Dental pain or bleeding gums & $333(47.0 \%)$ \\
\hline \multirow{3}{*}{ Reasons for visiting the dentist } & Esthetics & $150(21.1 \%)$ \\
\hline & Routine check-ups & $155(21.9 \%)$ \\
\hline & Wouldn't see the dentist no matter what & $71(10.0 \%)$ \\
\hline \multirow{4}{*}{ Reasons for not visiting the dentist } & Fear & $243(34.3 \%)$ \\
\hline & Cost & $32(4.5 \%)$ \\
\hline & Lack of a nearby clinic/distance & $83(11.7 \%)$ \\
\hline & Lack of time & $208(29.3 \%)$ \\
\hline \multirow{5}{*}{ Person's evaluation of his/her oral health } & Others & $140(19.7 \%)$ \\
\hline & Excellent & $177(25.0 \%)$ \\
\hline & Good & 458 (64.6\%) \\
\hline & Bad & 68 (9.6\%) \\
\hline & Didn’t know & $6(0.8 \%)$ \\
\hline \multicolumn{2}{|c|}{ Total } & $709(100 \%)$ \\
\hline
\end{tabular}

Among reasons for visiting the dentist, "dental pain or bleeding gums" was the most reported reason according to dental and engineering students (48.3\% and 25.5\%) and the only reason in cases of computer sciences students. Esthetics was the main reason for medicine, nursing, and science and literature students $(24.0 \%, 6.7 \%$, and $22.7 \%$, respectively). Gender-wise, females primarily visited the dentist for esthetic reasons (70\%) and males upon complaint (59.8\%). Of those who wouldn't see the dentist no matter what dental students comprised (35.2\%). A person's evaluation of oral health revealed that most students perceived their oral health as good (64.6\%). Dental students were the majority among all disciplines to perceive their oral health as excellent (68.9\%) and good (33.2\%).

\section{Discussion}

The importance of this study lies in the fact that students from all disciplines were surveyed, and not only dental or other specialties as previous studies have done [4]-[14].

Knowledge about the timing of the first dental visit was poor; this finding might be one of the risk factors for the high rates of early childhood caries. As expected, dental students were the highest among all to use auxiliary oral hygiene aids and base their choice of toothpaste upon fluoride content, but pharmacy students were the highest to use Chlorhexidine ${ }^{\circledR}$ mouth-rinse [92.6\%] reflecting the educational background of these students. Education, socio-economic conditions, psychological stress, and cultural and religious beliefs can affect oral health knowledge, behavior and practices [15]-[17].

Cross-cultural studies conducted among dental students showed that oral health behavior was different among different cultures [18]-[21]. For example, use of miswak/siwak as an oral hygiene device was common in the Saudi population [39.9\%] and this can be related to cultural and religious beliefs in addition to low cost and 
availability [22]. In the student sample studied, siwak was used by 33.9\% of the students.

Studies have shown that oral health practices are determined by gender and females consistently exhibit significantly higher rates of good oral health behavior [17] [23]. Gender differences and better oral health knowledge and practices were found among the sample studied and this may reflect their interest in maintaining good appearance [24]. Due to higher female concerns about body and facial image, they would, thus, be more concerned about seeking regular dental care and possess better oral health awareness [13].

The oral hygiene practices of the sample were similar to other studies since [52.6\%] reported twice daily frequency of brushing and only [33.9\%] reported flossing. Frequency of tooth-brushing and the use of dental floss have been investigated in many studies. Most studies report a high rate of twice daily or more tooth-brushing, yet the frequency of dental floss use remains low [4] [11] [15] [25]. For example, [67.6\%] of Turkish and [92.1\%] of Italian university students brushed their teeth twice or more a day, however, regular dental flossing was only reported in [3\%] of Turkish and [14.9\%] of Italian university students [14] [25].

The unexpected high sugar intake among dental students might be related to reliance on oral hygiene and auxiliary aids as a major preventive measure, or access to dental care when needed. However, this fact is worth further investigations. In agreement with previous studies, our results suggest that in spite of access to free dental care provided by the dental colleges, periodic dental check-ups were only common among nearly one-third of the students [1] [26] [27]. A previous study showed that $80 \%$ of Jordanian adults received dental care irregularly; and the reason for dental visits was for emergencies, i.e., pain [26]. In another study, $47 \%$ of a sample of dental, dental technology and dental hygiene students delayed dental care until they had a toothache [27].

Results of the present study indicate students' dental care seeking behavior at a university dental clinic for preventive check-ups was lower [29.1\%] than in an Italian university [59.9\%] [25] and nearly the same as in a Turkish university [30.3\%] [14]. Oral hygiene practices in developing countries like Jordan are based upon tradition and culture with prevalent use of indigenous substances [26]. It has been noticed that most health beliefs and practices are learned and practiced at home; and professional help is only sought when home remedies fail [27]. However, strong reliance on self-care may undermine the effectiveness of organized oral health care by delaying dental visits or considering them unnecessary [7].

Finally, most of the students had distorted perceptions than what was actually the case; the majority perceived their oral health as being good [64.6\%] regardless of the poor frequency of oral health and preventive-related practices reported among them.

Therefore, it is the role of both dentists and dental hygienists who specialize in oral disease prevention to improve oral health knowledge and practices [21] [28]. The presence of a dental hygienist in health centers would lead to a paramount improvement in community dental health. Systematic oral health education programs should be implemented with all educational levels and ages to support the improvement of regular oral self-care practices and oral health [14].

\section{Conclusion}

The knowledge of university students was lower than what was expected from a population with high literacy as well as the poor oral health practices and dental service utilization in a sample with easy access to dental care. Dental students showed higher knowledge and better oral health practices among the disciplines studied. Based on the findings, dental students may serve as good role models for their colleagues and community. It is also very important that dental hygienists take an active role in educating students in the aspect of oral health.

\section{Limitations of the Study}

This study had limitations since it was based on a self-reported questionnaire therefore, answers may be biased, and subjects may also forget relevant details which may affect the results.

\section{Acknowledgements}

We would like to acknowledge the fifth year students/class of 2008 who contributed in the questionnaire distribution and data collection. The authors deny any conflicts of interest. We affirm that we have no financial affiliation (e.g., employment, direct payment, stock holdings, retainers, consultant-ships, patent licensing arrangements or honoraria), or involvement with any commercial organization with direct financial interest in the subject or materials discussed in this manuscript, nor have any such arrangements existed in the past three years. 


\section{References}

[1] Doshi, D., Baldava, P., Anup, N. and Sequeira, P.S. (2007) A Comparative Evaluation of Self-Reported Oral Hygiene Practices among Medical and Engineering University Students with Access to Health-Promotive Dental Care. Journal of Contemporary Dental Practice, 8, 68-75.

[2] Andersen, R., Marcus, M. and Mahshigan, M. (1995) A Comparative Systems Perspective on Oral Health Promotion and Disease Prevention. In: Cohen, L.K. and Gift, H.C., Eds., Disease Prevention and Oral Health Promotion. SocioDental Sciences in Action, 3rd Edition, Copenhagen, 307-340.

[3] Kawamura, M., Spadafora, A., Kim, K.J. and Komabayashi, T. (2002) Comparison of United States and Korean Dental Hygiene Students Using the Hiroshima University-Dental Behavioural Inventory (HU-DBI). International Dental Journal, 52, 156-162. http://dx.doi.org/10.1111/j.1875-595X.2002.tb00621.x

[4] Kumar, S. (2012) Oral Hygiene Awareness among Two Non Professional College Students in Chennai, India-A Pilot Study. Advances in Life Science and Technology, 5, 31-36.

[5] Al-Zarea, B.K. (2013) Oral Health Knowledge of Periodontal Disease among University Students. International Journal of Dentistry, 2013, Article ID: 647397. http://www.hindawi.com/journals/ijd/2013/647397/ http://dx.doi.org/10.1155/2013/647397

[6] Almas, K., Al-Hawish, A. and Al-Khamis, W. (2003) Oral Hygiene Practices, Smoking Habit, and Self-Perceived Oral Malodor among Dental Students. Journal of Contemporary Dental Practice, 4, 77-90.

[7] Komabayashi, T., Kwan, S.Y., Hu, D.Y., Kajiwara, K., Sasahara, H. and Kawamura, M. (2005) A Comparative Study of Oral Health Attitudes and Behaviour Using the Hiroshima University-Dental Behavioural Inventory (HU-DBI) between Dental Students in Britain and China. Journal of Oral Science, 47, 1-7. http://dx.doi.org/10.2334/josnusd.47.1

[8] Al-Omari, Q.D. and Hamasha, A.A. (2005) Gender-Specific Oral Health Attitudes and Behavior among Dental Students in Jordan. Journal of Contemporary Dental Practice, 6, 107-114.

[9] Ohshima, M., Zhu, L., Yamaguchi, Y., Kikuchi, M., Nakajima, I., Langham, C.S., Lin, W., Otsuka, K. and Komiyama, K. (2009) Comparison of Periodontal Health Status and Oral Health Behavior between Japanese and Chinese Dental Students. Journal of Oral Science, 51, 275-281. http://dx.doi.org/10.2334/josnusd.51.275

[10] Dagli, R.J., Tadakamadla, S., Dhanni, C., Duraiswamy, P. and Kulkarni, S. (2008) Self Reported Dental Health Attitude and Behavior of Dental Students in India. Journal of Oral Science, 50, 267-272. http://dx.doi.org/10.2334/josnusd.50.267

[11] Al-Hussaini, R., Al-Kandari, M., Hamadi, T., Al-Mutawa, A., Honkala, S. and Memon, A. (2003) Dental Health Knowledge, Attitudes and Behaviour among Students at the Kuwait University Health Sciences Centre. Medical Principles and Practice, 12, 260-265. http://dx.doi.org/10.1159/000072295

[12] Al-Ansari, J., Honkala, E. and Honkala, S. (2003) Oral Health Knowledge and Behavior among Male Health Sciences College Students in Kuwait. BMC Oral Health, 3, 2. http://dx.doi.org/10.1186/1472-6831-3-2

[13] Al-Wahadni, A.M., Al-Omiri, M.K. and Kawamura, M. (2004) Differences in Self-Reported Oral Health Behavior between Dental Students and Dental Technology/Dental Hygiene Students in Jordan. Journal of Oral Science, 46, 191197. http://dx.doi.org/10.2334/josnusd.46.191

[14] Kırtıloğlu, T. and Yavuz, U.S. (2006) An Assessment of Oral Self-Care in the Student Population of a Turkish University. Public Health, 120, 953-957. http://dx.doi.org/10.1016/j.puhe.2006.05.006

[15] Paulander, J., Axelsson, P. and Lindhe, J. (2003) Association between Level of Education and Oral Health Status in 35-, 50-, 65- and 75-Year-Olds. Journal of Clinical Periodontology, 30, 697-704. http://dx.doi.org/10.1034/j.1600-051X.2003.00357.x

[16] Koivusilta, L., Honkala, S., Honkala, E. and Rimpela, A. (2003) Toothbrushing as Part of the Adolescent Lifestyle Predicts Education Level. Journal of Dental Research, 82, 361-366. http://dx.doi.org/10.1177/154405910308200507

[17] Kassak, K.M., Dagher, R. and Doughan, B. (2001) Oral Hygiene and Lifestyle Correlates among New Undergraduate University Students in Lebanon. Journal of American College Health, 50, 15-20. http://dx.doi.org/10.1080/07448480109595706

[18] Kawamura, M., Iwamoto, Y. and Wright, F.A. (1997) A Comparison of Self-Reported Dental Health Attitudes and Behavior between Selected Japanese and Australian Students. Journal of Dental Education, 61, 354-360.

[19] Kawamura, M., Honkala, E., Widström, E. and Komabayashi, T. (2000) Cross-Cultural Differences of Self-Reported Oral Health Behaviour in Japanese and Finnish Dental Students. International Dental Journal, 50, 46-50. http://dx.doi.org/10.1111/j.1875-595X.2000.tb00546.X

[20] Kawamura, M., Yip, H.K., Hu, D.Y. and Komabayashi, T. (2001) A Cross-Cultural Comparison of Dental Health Attitudes and Behaviour among Freshman Dental Students in Japan, Hong Kong and West China. International Dental Journal, 51, 159-163. http://dx.doi.org/10.1002/j.1875-595X.2001.tb00833.x 
[21] Kawamura, M., Ikeda-Nakaoka, Y. and Sasahara, H. (2000) An Assessment of Oral Self-Care Level among Japanese Dental Hygiene Students and General Nursing Students Using the Hiroshima University-Dental Behavioural Inventory (HU-DBI): Surveys in 1990/1999. European Journal of Dental Education, 4, 82-88. http://dx.doi.org/10.1034/j.1600-0579.2000.040206.x

[22] Farsi, J.M., Farghaly, M.M. and Farsi, N. (2004) Oral Health Knowledge, Attitude and Behaviour among Saudi School Students in Jeddah City. Journal of Dentistry, 32, 47-53. http://dx.doi.org/10.1016/j.jdent.2003.08.002

[23] Tada, A. and Hanada, N. (2004) Sexual Differences in Oral Health Behaviour and Factors Associated with Oral Health Behaviour in Japanese Young Adults. Public Health, 118, 104-109. http://dx.doi.org/10.1016/j.puhe.2003.05.007

[24] Astrøm, A.N. (2004) Stability of Oral Health-Related Behaviour in a Norwegian Cohort between the Ages of 15 and 23 Years. Community Dentistry and Oral Epidemiology, 32, 354-362. http://dx.doi.org/10.1111/j.1600-0528.2004.00174.x

[25] Rimondini, L., Zolfanelli, B., Bernardi, F. and Bez, C. (2001) Self-Preventive Oral Behavior in an Italian University Student Population. Journal of Clinical Periodontology, 28, 207-211. http://dx.doi.org/10.1034/j.1600-051x.2001.028003207.x

[26] Taani, D.Q. (2002) Periodontal Awareness and Knowledge, and Pattern of Dental Attendence among Adults in Jordan. International Dental Journal, 52, 94-98. http://dx.doi.org/10.1111/j.1875-595X.2002.tb00607.x

[27] Schwarz, E.L. (1995) Oral Health and Dental Care in Hong Kong. International Dental Journal, 45, 169-176.

[28] Luciak-Donsberger, C. (2003) Origins and Benefits of Dental Hygiene Practice in Europe. International Journal of Dental Hygiene, 1, 29-42. http://dx.doi.org/10.1034/j.1601-5037.2003.00008.x 